\title{
Surgically modifiable factors measured by computer-navigation together with patient- specific factors predict knee society score after total knee arthroplasty
}

\author{
Frank Lampe ${ }^{1,3}$, Franziska Fiedler ${ }^{2}$, Carlos J. Marques ${ }^{1 *}$, Anusch Sufi-Siavach ${ }^{2}$ and Georg Matziolis ${ }^{4}$
}

\begin{abstract}
Background: The purpose was to investigate whether patient-specific factors (PSF) and surgically modifiable factors (SMF), measured by means of a computer-assisted navigation system, can predict the Knee Society Scores (KSS) after total knee arthroplasty (TKA).

Methods: Data from 99 patients collected during a randomized clinical trial were used for this secondary data analysis. The KSS scores of the patients were measured preoperatively and at 4-years follow-up. Multiple regression analyses were performed to investigate which combination of variables would be the best to predict the 4-years KSS scores.

Results: When considering SMF alone the combination of four of them significantly predicted the 4-years KSS-F score $(p=0.009)$, explaining $18 \%$ of its variation. When considering only PSF the combination of age and body weight significantly predicted the 4-years KSS-F $(p=0.008)$, explaining $11 \%$ of its variation. When considering both groups of predictors simultaneously the combination of three PSF and two SMF significantly predicted the 4-years KSS-F ( $p=0.007$ ), explaining $20 \%$ of its variation.
\end{abstract}

Conclusions: Younger age, better preoperative KSS-F scores and lower BMI before surgery, a positive tibial component slope and small changes in femoral offset were predictors of better KSS-F scores at 4-years.

Keywords: Total knee replacement, Computer-assisted surgery, Prognosis, Outcome assessment

\section{Background}

Total knee arthroplasty (TKA) is an effective and costefficient [1-3] intervention for end-stage knee osteoarthritis (OA). The outcomes by which the success of TKA can be measured are different. Pain relief and the restoration of functional activities have been reported as the main outcomes after primary TKA [4]. Other authors have focused on aspects influencing health-related quality of life (HRQL) [5-9] or patient satisfaction [10-12].

In the field of outcome-research there is an increasing interest in understanding the factors that influence and

\footnotetext{
* Correspondence: cmarques@schoen-kliniken.de

${ }^{1}$ Research Center of the Department of Orthopedics and Joint Replacement at the Schoen Klinik Hamburg Eilbek, Dehnhaide 120, D-22081 Hamburg, Germany

Full list of author information is available at the end of the article
}

may predict the results after TKA. In this context there are patient-specific factors (PSF) and surgically modifiable factors (SMF) that can be considered as potential predictors of outcomes. Examples of PSF are the preoperative range of movement (ROM) [13, 14], body mass index (BMI) [15] and the presence or absence of comorbidities [16, 17]. Under SMF one could consider, among others, the type of prosthesis used [18, 19], changes in posterior tibial slope (PTS) [14] and changes in posterior condylar offset (PCO) [14]. In the past these factors could only be assessed by radiographs, with the well-known limitations of radiometric morphometry. Using computer-navigation systems a large variety of biomechanical parameters can be monitored and saved intra-operatively. Several meta-analyses have shown that navigated TKA can reduce the number of radiographic 
outliers compared with traditional techniques, leading to significant improvements in prosthesis alignment and positioning [20-24].

From a clinician perspective, clinical scores are of great importance as endpoints because they are easy to apply. Their use is widespread, allowing comparisons between different populations. The knee society score (KSS) [25] is a validated rating system generally used to evaluate both the knee function and patient functional ability before and after TKA. With its KSS-Knee and KSS-Function sub-scores, it combines an objective physician-derived with a patient-subjective component. Pain relief, function and patient satisfaction can be evaluated.

The purpose of this study was to investigate the predictive value of PSF and SMF measured by means of a computer-assisted navigation system on the KSS ratings. It was hypothesized that a combination of PSF and SMF could explain a proportion of KSS variability at 4-years after surgery.

\section{Methods}

\section{Subjects}

This study is a secondary analysis of data obtained during a prospective randomized clinical trial designed to investigate the effects of mobile bearing (MB) vs. fixed-bearing (FB) TKA implants on clinical scores [26].

Ninety-nine patients (100 knees) scheduled for primary bicondylar, posterior cruciate retaining TKA at the Schoen Klinik Hamburg Eilbek were informed about the study and agreed to participate.

All patients met the following inclusion criteria: clinical and radiological signs of osteoarthritis of the knee with failed non-operative treatment; no indication for a uni-compartmental implant or joint-preserving osteotomies; age ranging from 40 to 90 years; American society of anaesthesiologists pre-operative classification grade $1-3$; no deformity larger than $20^{\circ}$ varus or $15^{\circ}$ valgus; no previous bone surgery to the index knee; no previous total joint replacement at the index leg; no postoperative infection of the index knee or thrombosis within the follow-up period.

The patients were randomly assigned into one of the groups. At baseline there were 52 patients in the FB and 48 in the MB group. At 4 years follow-up there was a loss of 7 patients $(13.5 \%)$ in the FB group (2 died with no relation to TKA; 5 did not attend the 4 years followup) and 6 patients (12.5\%) in the MB group (1 septic implant exchange before 12 months; 3 did not attend the 1 year follow-up; 1 died with no relation to TKA).

The mean age of the patients by entrance in the study was $69.1 \pm 7.8$ years. The distribution of female and male patients in the sample was 73 and 27, respectively. There was no significant difference between the mean ages of male and female patients $(p=0.7)$. The significant differences found when comparing the mean body weight $(p=0.02)$ and mean body height $(p<0.001)$ of both genders had no consequences in terms of mean BMI differences $(p=0.2)$. For further demographic data see Table 1.

Since there were no significant differences between the KSS scores in the fixed- and mobile-bearing groups at any measurement time, and no significant differences when comparing the ROM of both groups across the follow-up assessments [26], all patients were pooled into one group for the purpose of this secondary analysis of the data.

Before participating all patients were required to read and sign an informed consent form, in which their permission to anonymously save the navigation data registered during surgery for the purpose of this secondary data analysis was also requested. The medical Ethics Commission of the Federal State of Hamburg approved the research proposal (File \#2226). The trial was registered under ClinicalTrial.gov (NCT00822640).

\section{Materials}

The computer-assisted navigation system OrthoPilot TKA version 4.2 (BBraun Aesculap, Tuttlingen, Germany) was used to perform all surgeries. The system is based on intra-operatively acquired data. An infrared camera tracks infrared diodes, which have been previously fixed on the femoral and tibia bones, on a hand-held pointer and on the cutting blocks [27]. The optical tracking system used by OrthoPilot is the hybrid Polaris Spectra ${ }^{\circ}$ (Northern Digital Inc., Waterloo, Ontario, Canada). According to the supplier, the accuracy of the system is $0.25 \mathrm{~mm}$ RMS when applying the pyramid measurement volume method $[28,29]$.

The navigation system defines the mechanical axis of the leg. With navigation-adapted instruments the surgeon performs the femoral and tibial resection cuts under real-time control of the navigation parameters, allowing leg alignment corrections and soft-tissue balance. The reliability of leg alignment when using this system, as well as the reliability of the navigation guided gap technique were tested in the past in experimental settings [30, 31].

The extension and flexion gaps were measured after tibial cutting by the navigation system after introducing a device (Laminar spreader, BBraun Aesculap, Tutlingen, Germany) allowing independent tensioning of the medial and lateral joint gaps. Based on these measurements the femoral component size and position were planned, aiming to minimize gap inequalities and asymmetries as far as possible (tibia first technique). The measurement and calculation of the navigation variables was made on the bases of the 
Table 1 Demographic data of the sample by the time of entry in the study

\begin{tabular}{lllll}
\hline Variables & All & Female & Male & Mean Diff. (p-value) [95\% Cl] \\
Number of Patients & $n=100$ & $n=73$ & $n=27$ & $0.5(p=0.7)[-4.0$ to 2.9$]$ \\
\hline Age (years) & $69.1 \pm 7.8$ & $69.3 \pm 7.9$ & $68.7 \pm 7.4$ & $7.7(p=0.02)[0.8 \text { to } 14.6]^{(*)}$ \\
Body Weight $(\mathrm{Kg})$ & $82.6 \pm 15.7$ & $80.5 \pm 15.5$ & $88.2 \pm 14.8$ & $12.1(p<0.001)[9.2 \text { to } 15.0]^{(*)}$ \\
Body Height $(\mathrm{cm})$ & $167.1 \pm 8.4$ & $163.8 \pm 6.4$ & $176.0 \pm 6.4$ & $1.3(p=0.2)[-3.8$ to 1.1$]$ \\
BMl $\left(\mathrm{Kg} / \mathrm{m}^{2}\right)$ & $29.5 \pm 5.5$ & $29.9 \pm 5.7$ & $28.5 \pm 5.0$ & \\
\hline
\end{tabular}

Values are mean $\left.\pm S D ;{ }^{*}\right)=$ Significant difference

resected bone surfaces. No additional measurements were performed after the implantation of the implant components. Detailed information on the surgical procedure and workflow when using the OrthoPilot system were published previously [32].

\section{Measurements}

For the present purpose preoperative and follow-up data acquired at 4- years post-surgery by a trained physician were used.

All surgeries were performed by one of two senior surgeons. Navigation data were recorded during surgery. Some navigation variables were calculated post-surgery based on the data obtained intra-operatively.

The fifteen SMF used in this study are explained in Table 2. Furthermore, the following PSF were used: patient's age by the time of surgery, body weight, body height, BMI, preoperative maximal knee flexion (Pre-OP MKF) and preoperative KSS scores (Pre-OP KSS).

\section{Statistical analysis}

Mean and standard deviation were used to describe the data, since all predictor variables are continuous. Normal distribution of the data was confirmed with the Kolmogorov-Smirnov test. Demographic data comparisons between male and female patients in the sample were performed on baseline data with a $t$-test for independent samples (Table 2).

Multiple regression analyses to estimate the contribution of different independent variables (SMF and PSF) to the explanation of 4-years KSS (dependent variable) were carried out in three phases. In the first phase Pearson's correlation was used to assess the univariate association between each independent variable (potential predictors) and the 4-years KSS scores. A $p$-value $\leq 0.20$ was accepted as the level of significance to ensure that potentially relevant independent variables were not excluded at this stage as recommended in the literature [33]. In the second phase all independent variables that were significantly associated with the 4-years KSS-F

Table 2 Definition of the surgically modifiable factors (SMF)

\begin{tabular}{|c|c|c|c|}
\hline Name & Abbreviation & Definition & Values \\
\hline Femoral Joint Line Change max. & FJLCmax & Femoral joint line change from the most prominent condyle & Millimeter \\
\hline Femoral Joint Line Change min. & FJLCmin & Femoral joint line change from the less prominent condyle & Millimeter \\
\hline Femoral Component Slope & FS & Femoral component angle in the sagittal plane & Degrees \\
\hline Tibial Joint Line Change & TJLC & Tibial joint line change from the unworn compartment & Millimeter \\
\hline Tibial Component Slope & TCS & Tibial component angle in the sagittal plane & Degrees \\
\hline Extension Gap Size Medial & EGSmed & Medial gap between the femoral and tibial components in extension & Millimeter \\
\hline Extension Gap Size Lateral & EGSlat & Lateral gap between the femoral and tibial components in extension & Millimeter \\
\hline $\begin{array}{l}\text { Extension Gap Difference Medial- } \\
\text { Lateral }\end{array}$ & EGDM-L & Difference between EGSmed and EGSlat (EG symmetry) & Millimeter \\
\hline Flexion Gap Size Medial & FGSmed & Medial gap between the femoral and tibial components in $90^{\circ}$ flexion & Millimeter \\
\hline Flexion Gap Size Lateral & FGSlat & Lateral gap between the femoral and tibial components in $90^{\circ}$ flexion & Millimeter \\
\hline Flexion Gap Difference Medial-Lateral & FGDM-L & Difference between FGSmed and FGSlat (FG symmetry) & Millimeter \\
\hline Flexion Extension Gap Difference & FEGD & Difference between the mean EGS and the mean FGS (Gap equality) & Millimeter \\
\hline Femoral Offset Changes Medial & FOCmed & $\begin{array}{l}\text { Difference between the medial FO before and after femoral component } \\
\text { implantation }\end{array}$ & Millimeter \\
\hline Femoral Offset Changes Lateral & FOClat & $\begin{array}{l}\text { Difference between the lateral FO before and after femoral component } \\
\text { implantation }\end{array}$ & Millimeter \\
\hline Femoral Rotation & $\mathrm{FR}$ & Femoral rotation relative to the posterior condyle line & Degrees \\
\hline
\end{tabular}


score were entered into two backward multiple regression models. A stepping method criterion with a probability of $\mathrm{F}$ to remove $\geq 0.10$ was used. The first model included only SMF and the second model included only PSP. Finally, in the third phase, a final model was generated including selected SMF and PSF. The selection of the independent variables for the third model was made based on the results of the two previous procedures, on the literature and on surgeons empirical knowledge. Since the unstandardized regression coefficients (B) communicate the direction (positive or inverse) and the weighting of the independent variable (predictor) relative to the other independent variables in explaining the variation of the dependent variable, only predictors with a unstandardized coefficient, which could be explained according to the existing literature were included in the final model.

The three models met the assumptions of multiple regressions in terms of linearity, homoscedasticity, normality, independence and non-multicollinearity.

All statistical tests were carried out with the use of the IBM SPSS software version 21 for Mac. For all statistical tests the 0.05 level of probability was accepted as the criterion for statistical significance.

\section{Results}

The correlation coefficients between the 15 SMF and the 4-years KSS-Function scores are presented in Table 3. Only six had a significant linear relationship with the 4years KSS-F (Table 3). When considering only the SMF as potential predictors, the prediction model generated contained four of the six variables (FJLCmin, TCS, FGDM-L, FOCmed) and was reached in three steps (Table 4). The model was statistically significant, $\mathrm{F}_{(4,95)}=3.7, p=0.009$, and accounted for approximately $18 \%$ of the variance of the 4-year KSS-F score $\left(R^{2}=0.18\right.$, Adj. $\left.R^{2}=0.13\right)$. Three of the four predictors added statistically significantly to the prediction.

The correlation coefficients between PSF and the 4-years KSS-F scores are shown in Table 5. Four of the six PSF (body weight, BMI, age and Pre-OP KSS-F) had a significant linear relationship with the KSS-F score (Table 5). The prediction model generated contained two predictors (age and body weight) and was reached in three steps (Table 4). The model was statistically significant, $\mathrm{F}_{(2,97)}=5.1, p=0.008$, and explained approximately $11 \%$ of the variance of 4 -years KSS-F $\left(R^{2}=.11\right.$, Adj. $\left.R^{2}=.08\right)$. Both predictors added statistically significantly to the prediction.

Finally, the combination of BMI, age, Pre-OP KSSF, TCS and FOCmed significantly predicted 4-years KSS-F, $F_{(5,94)}=3.7, p=0.007$, and accounted for approximately $20 \%$ of the variance of 4-years KSS-F $\left(R^{2}=.20\right.$, Adj. $\left.R^{2}=.14\right)$. Lower BMI, younger age and higher KSS-F scores by the time of surgery, together with a positive (posterior) TCS and a good reconstruction (small changes) in FOCmed led to better KSS-F scores at 4-years. Only two of the five predictors added statistically significantly to the prediction (Table 4).

The correlation coefficients between SMF, PSF and the 4-years KSS-Knee scores are presented in Table 6. There were no significant correlations between the SMF and the KSS-Knee score at 4-years for a $p<0.05$. As described above, a $p$-value $\leq 0.20$ was accepted as the level of significance to ensure that potentially relevant independent variables were not excluded at this stage. Eight potential predictors (see Table 6) were selected and entered into a backward multiple regression model. The models created were not statistically significant. The same procedure was repeated for PSF. Again, no statistically significant models were found. A negative negligible relationship between KSS-K preoperatively and KSS-K at 4 -years was statistically significant $(p<0.05)$.

\section{Discussion}

The aim of the present study was to investigate, whether it is possible to predict the KSS scores based on PSF and SMF obtained during computerassisted TKA. The approach used is new. Fifteen potentially relevant SMF were accessed, which in part cannot be measured by radiographic morphometry. To the authors' best knowledge there are no publications available addressing such a high number of SMF. Neither are there any publications available addressing the relationships between PSF, SMF and the KSS ratings.

The key findings of the present study are: (1) PSF could explain $11 \%$ of the 4-years KSS-F scores variability; (2) four SMF could explain $18 \%$ of the 4-years KSS-F variability, however, the unstandardized coefficients (B) of two of the factors considered in the model (FJCmin and FGDM-L) could not be explained, therefore these factors were excluded from the final model; (3) a combination of PSF and SMF could explain the largest proportion (20\%) of the 4-years KSS-F variation.

According to the present results, older age, higher BMI and lower preoperative KSS-F ratings are preconditions that negatively influence the 4-years KSS-Function outcomes.

Several meta-analyses have shown that navigated TKA significantly improves prosthesis alignment, component position and limb alignment [34-36]. Only a few reports have shown that navigation can result in improved functional outcomes in TKA [21,37].

In a meta-analysis investigating the influence of BMI on the outcomes of primary TKA a trend was reported 
Table 3 Correlations between surgically modifiable factors (SMF) and 4-years KSS-F scores

\begin{tabular}{|c|c|c|c|c|c|c|c|c|c|c|c|c|c|c|c|c|}
\hline $\begin{array}{l}\text { Potential Predictor (Surgically } \\
\text { modifiable variables) }\end{array}$ & KSS-F & FJLCmax & FJLCmin & FS & TJLC & TCS & EGSmed & EGSlat & EGDM-L & FGSmed & FGSlat & FGDM-L & FEGD & FOCmed & FOClat & FR \\
\hline $\begin{array}{l}\text { Femoral Joint Line Change max } \\
\text { (FJLCmax) }\end{array}$ & $.25^{*}$ & & & & & & & & & & & & & & & \\
\hline $\begin{array}{l}\text { Femoral Joint Line Change min } \\
\text { (FJLCmin) }\end{array}$ & $.29^{*}$ & $.52^{*}$ & & & & & & & & & & & & & & \\
\hline Femoral Component Slope (FS) & -.04 & -.06 & $-.23^{*}$ & & & & & & & & & & & & & \\
\hline Tibial Joint Line Change (TJLC) & -.02 & $-.37^{*}$ & -.16 & -.14 & & & & & & & & & & & & \\
\hline Tibial Component Slope (TCS) & $.22^{*}$ & .07 & -.02 & $.30^{*}$ & -.00 & & & & & & & & & & & \\
\hline Extension Gap Size Medial (EGSmed) & .05 & .07 & -.00 & .00 & $-.24^{*}$ & -.02 & & & & & & & & & & \\
\hline Extension Gap Size Lateral (EGSlat) & .03 & $.32^{*}$ & -.17 & .17 & $-.33^{*}$ & .14 & .20 & & & & & & & & & \\
\hline $\begin{array}{l}\text { Extension Gap Difference Med-Lat } \\
\text { (EGDM-L) }\end{array}$ & .08 & -.04 & .13 & -.02 & .00 & .03 & $-.22^{*}$ & $.31^{*}$ & & & & & & & & \\
\hline Flexion Gap Size Medial (FGSmed) & .05 & $-.29^{*}$ & -.15 & .08 & .17 & -.09 & -.07 & -.16 & -.11 & & & & & & & \\
\hline Flexion Gap Size Lateral (FGSlat) & -.04 & $-.30^{*}$ & -.02 & .08 & .13 & -.12 & -.08 & -.18 & -.03 & $.71^{*}$ & & & & & & \\
\hline $\begin{array}{l}\text { Flexion Gap Difference Med-Lat } \\
(\text { FGDM-L) }\end{array}$ & $.16^{* *}$ & .05 & .06 & -.01 & .09 & .04 & .00 & .05 & .08 & .05 & $-.41^{*}$ & & & & & \\
\hline $\begin{array}{l}\text { Flexion-Extension Gap Difference } \\
\text { (FEGD) }\end{array}$ & -.02 & $-.36^{*}$ & -.02 & -.03 & $.37^{*}$ & -.07 & $-.34^{*}$ & $-.53^{*}$ & -.02 & $.54^{*}$ & $.62^{*}$ & -.18 & & & & \\
\hline $\begin{array}{l}\text { Femoral Offset Changes Medial } \\
\text { (FOCmed) }\end{array}$ & $-.17^{* *}$ & $.25^{*}$ & .11 & -.00 & $-.36^{*}$ & .05 & $.26^{*}$ & .17 & -.02 & $-.29^{*}$ & $-.54^{*}$ & $.31^{*}$ & $-.45^{*}$ & & & \\
\hline $\begin{array}{l}\text { Femoral Offset Changes Lateral } \\
\text { (FOClat) }\end{array}$ & $-.14^{* *}$ & $.33^{*}$ & .12 & -.00 & $-.33^{*}$ & .07 & $.25^{*}$ & $.23^{*}$ & .03 & $-.36^{*}$ & $-.50^{*}$ & $.30^{*}$ & $-.45^{*}$ & $.90^{*}$ & & \\
\hline Femoral Rotation (FR) & .05 & .16 & .07 & -.03 & .16 & -.01 & -.08 & .05 & .09 & -.05 & .18 & -.04 & .08 & $-.33^{*}$ & .08 & \\
\hline Mean \pm SD & $85.2 \pm 15.6$ & $1.5 \pm 1.9$ & $0.7 \pm 2.3$ & $0.1 \pm 1.2$ & $3.0 \pm 1.7$ & $3.9 \pm 1.1$ & $0.6 \pm 1.2$ & $1.7 \pm 2.1$ & $1.9 \pm 1.4$ & $3.1 \pm 1.4$ & $2.8 \pm 1.6$ & $0.7 \pm 0.9$ & $2.2 \pm 1.6$ & $2.6 \pm 2.7$ & $0.3 \pm 2.5$ & $3.4 \pm 1.3$ \\
\hline
\end{tabular}

${ }^{(*)} p<.05 ;{ }^{(* *)} p<.20$ (Statistically significant linear relationship to $4-Y$ KSS-F in bold) 
Table 4 Multiple regression models for 4-years KSS-F scores

\begin{tabular}{|c|c|c|c|c|c|c|c|c|c|c|}
\hline & Dependent variable & Step & Predictors included & Predictors excluded & $R^{2}$ & Adj. $R^{2}$ & $\mathrm{~F}$ & $p^{*}$ & $\mathrm{~B}$ & $p^{* *}$ \\
\hline \multirow[t]{6}{*}{$1^{\text {st }}$ Model (only SMF) } & \multirow[t]{6}{*}{ 4-years KSS-F } & 1 & All six & & 0.20 & 0.12 & 2.6 & 0.02 & & \\
\hline & & 2 & & FOClat & 0.20 & 0.13 & 3.1 & 0.01 & & \\
\hline & & 3 & FJLCmin & FJLCmax & 0.18 & 0.13 & 3.7 & 0.009 & 1.7 & 0.02 \\
\hline & & & TCS & & & & & & 2.8 & 0.04 \\
\hline & & & FGDM-L & & & & & & 3.7 & 0.03 \\
\hline & & & FOCmed & & & & & & -1.3 & 0.05 \\
\hline \multirow[t]{4}{*}{$2^{\text {nd }}$ Model (only PSF) } & \multirow[t]{4}{*}{ 4-years KSS-F } & 1 & All four & & 0.11 & 0.07 & 11.4 & 0.04 & & \\
\hline & & 2 & & BMI & 0.11 & 0.08 & 3.5 & 0.01 & & \\
\hline & & 3 & Age & Pre-OP KSS-F & 0.11 & 0.08 & 5.1 & 0.008 & -0.2 & 0.04 \\
\hline & & & Body Weight & & & & & & -0.6 & 0.03 \\
\hline \multirow{5}{*}{$\begin{array}{l}3^{\text {rd }} \text { Model (combination } \\
\text { of PSF and SMF) }\end{array}$} & \multirow[t]{5}{*}{ 4-years KSS-F } & 1 & BMl & & 0.20 & 0.14 & 3.4 & 0.007 & -0.7 & 0.02 \\
\hline & & & Age & & & & & & -0.7 & 0.001 \\
\hline & & & Pre-OP KSS-F & & & & & & 0.04 & 0.5 \\
\hline & & & TCS & & & & & & 2.2 & 0.1 \\
\hline & & & FOCmed & & & & & & -0.7 & 0.2 \\
\hline
\end{tabular}

$p^{*}=$ Statistical significance of the model; $\mathrm{B}=$ Unstandardized Coefficients; $p^{* *}=$ Statistical significance of the predictors included in the final model Significant $p$-values in bold; SMF Surgically modifiable factors, PSF Patient-specific factors

for a lower postoperative $\mathrm{KSS}$ in obese $\left(\mathrm{BMI} \geq 30 \mathrm{~kg} / \mathrm{m}^{2}\right)$ patients than in non-obese $\left(\mathrm{BMI}<30 \mathrm{~kg} / \mathrm{m}^{2}\right)$ patients [38]. The present results reinforce this finding.

There is some evidence supporting the hypothesis that SMF, like the PTS and the PCO, influence the maximal knee flexion (MKF) after TKA [14, 39-43]. Since knee flexion is also assessed by the KSS and influences the performance of functional activities, it was hypothesized that these variables could probably predict 4-years KSSF. According to the expectations and reinforcing the above mentioned studies, the "Tibial Component Slope" (TCS) and the "Femoral Offset Changes Medial" (FOCmed) were considered in the final model, as predictors of the 4-years KSS-F. Higher positive TCS values (which represents the same as higher posterior TCS values) were significant predictors of a higher 4years KSS-F score. Small or no changes in FOC (the same as PCO), were also significant predictors of better 4-years KSS-F scores. The present results support the ones of the above referred studies.

For the present sample the strongest predictors of 4-years KSS-F were the TCS, followed by BMI and Age. The present results support early knee replacement surgery once "Age" was significantly negatively correlated with 4-years KSS-F scores. Furthermore the "Pre-OP KSS-F" score was positively correlated with "4-years KSS-F" (Table 5).

Surprisingly, no significant predictors of KSS-K score were found, neither among SMF, nor among PSF. KSS-K is the more objective KSS score, since it is based on the assessor measurements. The authors have no explanation for this finding. Maybe the conversion of the more objective data into to the KSS-K score, with the use an algorithm, is behind this findings.

Due to the fact that this study is a secondary analysis of data, a prospectively performed power analysis wasn't

Table 5 Correlations between patient-specific factors (PSF) and 4-years KSS-F scores

\begin{tabular}{|c|c|c|c|c|c|c|c|}
\hline Potential & 4-years & Body & Body & $\mathrm{BMl}$ & Age & Pre-OP & Pre-OP \\
\hline Predictors & KSS-F & Weight & Height & & & KSS-F & MKF \\
\hline Body Weight & $-.11^{* *}$ & & & & & & \\
\hline Body Height & -.04 & $.31^{*}$ & & & & & \\
\hline BMI & $-.09^{* *}$ & $.86^{*}$ & $-.20^{*}$ & & & & \\
\hline Age & $-.25^{*}$ & $-.35^{*}$ & -.13 & $-.31^{*}$ & & & \\
\hline Pre-OP KSS-F & $.08^{* *}$ & -.09 & .04 & -.12 & -.01 & & \\
\hline Pre-OP MKF & .03 & -.00 & $.19^{*}$ & -.09 & -.12 & .08 & \\
\hline Mean \pm SD & $85.0 \pm 15.1$ & $83.4 \pm 15.9$ & $167.1 \pm 8.5$ & $29.9 \pm 5.6$ & $68.9 \pm 7.9$ & $48.5 \pm 19.8$ & $110.0 \pm 14.2$ \\
\hline
\end{tabular}

${ }^{(*)} p<.05 ;{ }^{(*)} \mathrm{p}<.20$; Statistically significant linear relationship to $4-\mathrm{Y}$ KSS-F score in bold. MKF maximal knee flexion 
Table 6 Correlations between SMF, PSF and 4-years KSS-Knee scores

\begin{tabular}{ll}
\hline Potential predictors surgically modifiable variables & KSS-K \\
\hline Femoral Joint Line Change max (FJLCmax) & $.18^{* *}$ \\
Femoral Joint Line Change min (FJLCmin) & $.12^{* *}$ \\
Femoral Component Slope (FS) & .06 \\
Tibial Joint Line Change (TJLC) & -.06 \\
Tibial Component Slope (TCS) & $.18^{* *}$ \\
Extension Gap Size Medial (EGSmed) & .06 \\
Extension Gap Size Lateral (EGSlat) & $.16^{* *}$ \\
Extension Gap Difference Med-Lat (EGDM-L) & $.21^{* *}$ \\
Flexion Gap Size Medial (FGSmed) & .01 \\
Flexion Gap Size Lateral (FGSlat) & -.09 \\
Flexion Gap Difference Med-Lat (FGDM-L) & -.09 \\
Flexion-Extension Gap Difference (FEGD) & $-.16^{* *}$ \\
Femoral Offset Changes Medial (FOCmed) & $-.11^{* *}$ \\
Femoral Offset Changes Lateral (FOClat) & -.07 \\
Femoral Rotation (FR) & $.11^{* *}$ \\
Patient-specific factors & \\
Body weight & -.11 \\
Body height & $-.04^{* *}$ \\
BMI & $-.09^{* *}$ \\
Age & .00 \\
KSS-K Preoperatively & $-.17^{*}$ \\
Maximal knee Flexion (MKF) Preoperatively & -.04 \\
Mean (KSS-K) \pm SD & $87.2 \pm 10.3$ \\
\hline Potential predictors with a statistically significant linear relationship for \\
(*) p< 0.5 or ${ }^{(* *)}$ p< .20 in bold & \\
&
\end{tabular}

possible. This is a study limitation. Further studies on this issue should be prospectively statistically powered. A second study limitation is related to the fact that comorbidities were not accessed by the time the patients entered the study. Co-morbidities may significantly predict the results and should be accessed in further studies. A third study limitation concerns the fact that navigation data were obtained based on measurements upon the resected bone surfaces and further calculated by the software of the OrthoPilot system. Future studies on this matter should consider additional measurements after final implantation of the components, since the depth of cement mantle may influence the implant position and consequently the measured gaps.

The results of studies in this area could be used to identify patients at risk of poor outcomes submitting for TKA, as suggested by Lungu et al. [44]. The use of a regression equation prior to surgery to identify patients at risk could help to choose the appropriate course, such as pre-rehabilitation, participation in a weight-loss program before surgery or intensive post-operative rehabilitation.

\section{Conclusions}

Computer-navigation is a suitable tool to accurately measure and control a variety of SMF, which seem to affect clinical outcomes after TKA. Two PSF alone accounted for $11 \%$ of the 4-years KSS-F variation. A combination of three PSF and two SMF explained $20 \%$ of the 4-years KSS-F variability. According to the results of the present study, younger age, better preoperative KSS-F scores and lower BMI before surgery, a positive (posterior) Tibial Component Slope (TCS) and small changes in Femoral Offset (FOC) were predictors of better KSS-F scores at 4-years after TKA.

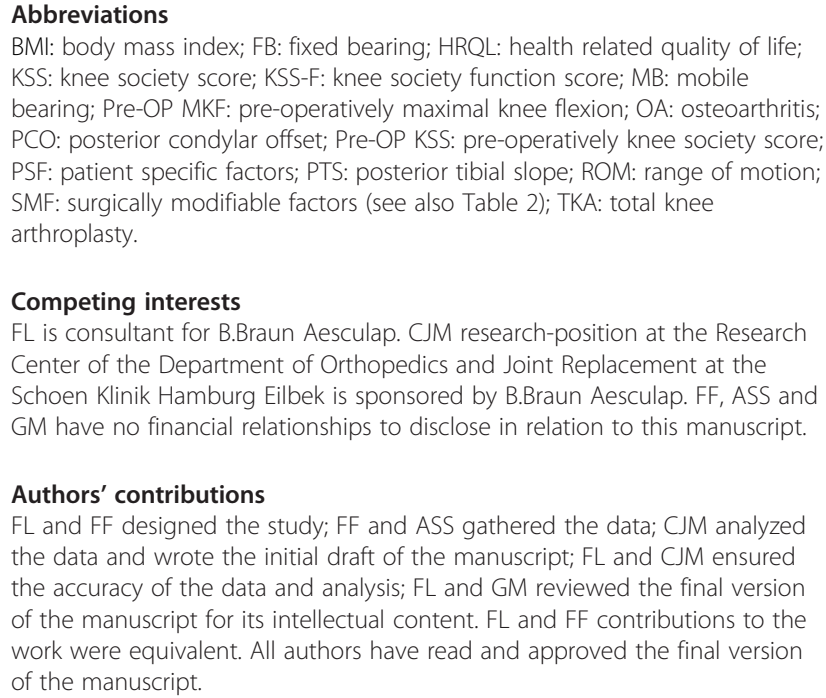

Competing interests

FL is consultant for B.Braun Aesculap. CJM research-position at the Research Center of the Department of Orthopedics and Joint Replacement at the Schoen Klinik Hamburg Eilbek is sponsored by B.Braun Aesculap. FF, ASS and GM have no financial relationships to disclose in relation to this manuscript.

Authors' contributions

FL and FF designed the study; FF and ASS gathered the data; CJM analyzed the data and wrote the initial draft of the manuscript; FL and CJM ensured the accuracy of the data and analysis; FL and GM reviewed the final version of the manuscript for its intellectual content. FL and FF contributions to the work were equivalent. All authors have read and approved the final version of the manuscript.

Acknowledgements

The authors would like to thank Dr. Bishop for proof reading the final version of the manuscript.

Level of Evidence

Level II, Prognostic study.

\section{Author details}

${ }^{1}$ Research Center of the Department of Orthopedics and Joint Replacement at the Schoen Klinik Hamburg Eilbek, Dehnhaide 120, D-22081 Hamburg, Germany. ${ }^{2}$ Department of Orthopedics and Joint Replacement at the Schoen Klinik Hamburg Eilbek, Dehnhaide 120, D-22081 Hamburg, Germany. ${ }^{3}$ Faculty of Life Sciences at the Hamburg University of Applied Sciences, Lohbrügger Kirchstraße 65, D-21033 Hamburg, Germany. ${ }^{4}$ Orthopaedic Department, Jena University Hospital, Campus Eisenberg, Klosterlausnitzer Straße 81, D-07607 Eisenberg, Germany.

Received: 27 August 2015 Accepted: 6 February 2016

Published online: 13 February 2016

\section{References}

1. Daigle ME, Weinstein AM, Katz JN, Losina E. The cost-effectiveness of total joint arthroplasty: a systematic review of published literature. Best Pract Res Clin Rheumatol. 2012;26(5):649-58.

2. Krummenauer F, Wolf C, Gunther KP, Kirschner S. Clinical benefit and cost effectiveness of total knee arthroplasty in the older patient. Eur J Med Res. 2009;14:76-84.

3. Losina E, Walensky RP, Kessler CL, Emrani PS, Reichmann WM, Wright EA, et al. Cost-effectiveness of total knee arthroplasty in the United States: patient risk and hospital volume. Arch Intern Med. 2009:169(12):1113-21. discussion 1121-1112. 
4. Lingard EA, Katz JN, Wright EA, Sledge CB. Predicting the outcome of total knee arthroplasty. J Bone Joint Surg Am. 2004;86-A(10):2179-86.

5. Alentorn-Geli E, Leal-Blanquet J, Guirro P, Hinarejos P, Pelfort X, Puig-Verdie L. Comparison of quality of life between elderly patients undergoing TKA. Orthopedics. 2013;36(4):e415-9.

6. Brandes $M$, Ringling M, Winter C, Hillmann A, Rosenbaum D. Changes in physical activity and health-related quality of life during the first year after total knee arthroplasty. Arthritis Care Res. 2011;63(3):328-34.

7. Bruyere $O$, Ethgen $O$, Neuprez A, Zegels B, Gillet P, Huskin JP, et al. Healthrelated quality of life after total knee or hip replacement for osteoarthritis: a 7-year prospective study. Arch Orthop Trauma Surg. 2012;132(11):1583-7.

8. Jones CA, Pohar S. Health-related quality of life after total joint arthroplasty: a scoping review. Clin Geriatr Med. 2012;28(3):395-429.

9. Papakostidou I, Dailiana ZH, Papapolychroniou T, Liaropoulos L, Zintzaras E, Karachalios TS, et al. Factors affecting the quality of life after total knee arthroplasties: a prospective study. BMC Musculoskelet Disord. 2012;13:116

10. Jacobs CA, Christensen CP. Factors influencing patient satisfaction two to five years after primary total knee arthroplasty. J Arthroplast. 2014;29(6):1189-91.

11. Jacobs CA, Christensen CP, Karthikeyan T. Patient and intraoperative factors influencing satisfaction two to five years after primary total knee arthroplasty. J Arthroplast. 2014;29(8):1576-9.

12. Williams DP, O'Brien S, Doran E, Price AJ, Beard DJ, Murray DW, et al. Early postoperative predictors of satisfaction following total knee arthroplasty. Knee. 2013;20(6):442-6.

13. Bade MJ, Kittelson JM, Kohrt WM, Stevens-Lapsley JE. Predicting functional performance and range of motion outcomes after total knee arthroplasty. Am J Phys Med Rehabil. 2014;93(7):579-85.

14. Malviya A, Lingard EA, Weir DJ, Deehan DJ. Predicting range of movement after knee replacement: the importance of posterior condylar offset and tibial slope. Knee Surg Sports Traumatol Arthrosc. 2009;17(5):491-8.

15. Gadinsky NE, Ehrhardt JK, Urband C, Westrich GH. Effect of body mass index on range of motion and manipulation after total knee arthroplasty. J Arthroplast. 2011;26(8):1194-7.

16. Issa K, Jauregui JJ, Given K, Harwin SF, Mont MA. A prospective, longitudinal study of patient activity levels following total knee arthroplasty stratified by demographic and comorbid factors. J Knee Surg. 2015;28(4):343-7.

17. Pugely AJ, Martin CT, Gao Y, Belatti DA, Callaghan JJ. Comorbidities in patients undergoing total knee arthroplasty: do they influence hospital costs and length of stay? Clin Orthop Relat Res. 2014:472(12):3943-50.

18. Bin SI, Nam TS. Early results of high-flex total knee arthroplasty: comparison study at 1 year after surgery. Knee Surg Sports Traumatol Arthrosc. 2007:15(4):350-5.

19. Huang HT, Su JY, Wang GJ. The early results of high-flex total knee arthroplasty: a minimum of 2 years of follow-up. J Arthroplast. 2005:20(5):674-9.

20. Bae DK, Song SJ. Computer assisted navigation in knee arthroplasty. Clin Orthop Surg. 2011:3(4):259-67.

21. Clayton AW, Cherian JJ, Banerjee S, Kapadia BH, Jauregui JJ, Harwin SF, et al. Does the use of navigation in total knee arthroplasty affect outcomes? J Knee Surg. 2014;27(3):171-5.

22. Fu Y, Wang M, Liu Y, Fu Q. Alignment outcomes in navigated total knee arthroplasty: a meta-analysis. Knee Surg Sports Traumatol Arthrosc. 2012;20(6):1075-82.

23. Hetaimish BM, Khan MM, Simunovic N, Al-Harbi HH, Bhandari M, Zalzal PK. Meta-analysis of navigation vs conventional total knee arthroplasty. J Arthroplast. 2012;27(6):1177-82

24. Thienpont E, Fennema P, Price A. Can technology improve alignment during knee arthroplasty. Knee. 2013;20 Suppl 1:S21-8.

25. Insall JN, Dorr LD, Scott RD, Scott WN. Rationale of the Knee Society clinical rating system. Clin Orthop Relat Res. 1989;248:13-4

26. Marques CJ, Daniel S, Sufi-Siavach A, Lampe F. No differences in clinical outcomes between fixed- and mobile-bearing computer-assisted total knee arthroplasties and no correlations between navigation data and clinical scores. Knee Surg Sports Traumatol Arthrosc. 2015;23(6):1660-8.

27. Clemens $U$, Miehlke RK. Advanced navigation planning including soft tissue management. Orthopedics. 2005;28(10 Suppl):s1259-62.

28. Nothern Digital Incorporation: Polaris Optical Tracking Systems (2015). http://www.ndigital.com/medical/products/polaris-family/\#specifications. Accessed 8 December 2015.
29. Wiles AD, Thompsen DG, Frantz DD. Accuracy assessment and interpretation for optical tracking systems. In: Medical Imaging 2004: Visualisation, Image-Guided Procedures and Display: 2004; San Diego, California, USA. 2004. p. 421-32.

30. Han SB, Nha KW, Yoon JR, Lee DH, Chae IJ. The reliability of navigationguided gap technique in total knee arthroplasty. Orthopedics. 2008; 31 (10 Suppl 1)

31. Hauschild O, Konstantinidis L, Strohm PC, Niemeyer P, Suedkamp NP, Helwig P. Reliability of leg alignment using the OrthoPilot system depends on knee position: a cadaveric study. Knee Surg Sports Traumatol Arthrosc. 2009:17(10):1143-51.

32. Lampe F, Hille E. Navigated Implantation of the Columbus Total Knee Arthroplasty with the OrthoPilot System: Version 4.0. In: Navigation and Robotics in Total Joint and Spine Surgery. edn.: Springer Berlin Heidelberg; 2004: 248-253.

33. Katz MH. Multivariate Analysis: A Practical Guide for Clinicians and Public Health Researchers. Cambridge: Cambridge University Press; 2011.

34. Mason JB, Fehring TK, Estok R, Banel D, Fahrbach K. Meta-analysis of alignment outcomes in computer-assisted total knee arthroplasty surgery. J Arthroplast. 2007;22(8):1097-106.

35. Quack VM, Kathrein S, Rath B, Tingart M, Luring C. Computer-assisted navigation in total knee arthroplasty: a review of literature. Biomedizinische Technik Biomedical engineering. 2012;57(4):269-75.

36. Venkatesan M, Mahadevan D, Ashford RU. Computer-assisted navigation in knee arthroplasty: a critical appraisal. J Knee Surg. 2013;26(5):357-61.

37. Moskal JT, Capps SG, Mann JW, Scanelli JA. Navigated versus conventional total knee arthroplasty. J Knee Surg. 2014;27(3):235-48.

38. Si HB, Zeng Y, Shen B, Yang J, Zhou ZK, Kang PD, et al. The influence of body mass index on the outcomes of primary total knee arthroplasty. Knee Surg Sports Traumatol Arthrosc. 2015;23(6):1824-32.

39. Fujimoto E, Sasashige $Y$, Masuda $Y$, Hisatome T, Eguchi A, Masuda T, et al. Significant effect of the posterior tibial slope and medial/lateral ligament balance on knee flexion in total knee arthroplasty. Knee Surg Sports Traumatol Arthrosc. 2013;21(12):2704-12.

40. Hohmann E, Bryant A, Reaburn P, Tetsworth K. Does posterior tibial slope influence knee functionality in the anterior cruciate ligamentdeficient and anterior cruciate ligament-reconstructed knee? Arthroscopy. 2010;26(11):1496-502.

41. Kim JH. Effect of posterior femoral condylar offset and posterior tibial slope on maximal flexion angle of the knee in posterior cruciate ligament sacrificing total knee arthroplasty. Knee Surg Relat Res. 2013;25(2):54-9.

42. Shi $X$, Shen B, Kang P, Yang J, Zhou Z, Pei F. The effect of posterior tibial slope on knee flexion in posterior-stabilized total knee arthroplasty. Knee Surg Sports Traumatol Arthrosc. 2013;21(12):2696-703.

43. Singh G, Tan JH, Sng BY, Awiszus F, Lohmann CH, Nathan SS. Restoring the anatomical tibial slope and limb axis may maximise post-operative flexion in posterior-stabilised total knee replacements. Bone Joint J. 2013:95-B(10):1354-8

44. Lungu E, Desmeules F, Dionne CE, Belzile EL, Vendittoli PA. Prediction of poor outcomes six months following total knee arthroplasty in patients awaiting surgery. BMC Musculoskelet Disord. 2014;15(1):299.

\section{Submit your next manuscript to BioMed Central and we will help you at every step:}

- We accept pre-submission inquiries

- Our selector tool helps you to find the most relevant journal

- We provide round the clock customer support

- Convenient online submission

- Thorough peer review

- Inclusion in PubMed and all major indexing services

- Maximum visibility for your research

Submit your manuscript at www.biomedcentral.com/submit 